\title{
Environmental control of morphine withdrawal: Context specificity or stimulus novelty?
}

\author{
ROBERT V. MCDONALD and SHEPARD SIEGEL \\ McMaster University, Hamilton, Ontario, Canada
}

\begin{abstract}
Past investigations of context-specific morphine withdrawal have demonstrated that when rats are tested while undrugged, withdrawal behaviors are more pronounced in an environment previously paired with drug administration than in an environment previously paired with saline administration (even in rats that have had exposure to only low doses of morphine prior to testing). In these studies, rearing is a commonly used index of morphine withdrawal. Rearing is also an exploratory behavior. The higher levels of rearing displayed in a morphine-paired, compared with a saline-paired, environment may be a manifestation of a tendency to explore this environment, rather than a tendency to display withdrawal symptoms in this environment. We evaluated the extent to which rearing and other measures of morphine withdrawal are displayed in drug-paired, saline-paired, and novel environments. The results suggest that, in some cases, apparent context specificity of morphine withdrawal actually results from novelty-elicited exploration.
\end{abstract}

As discussed by a number of investigators (e.g., Dworkin, 1993; Ramsay \& Woods, 1997; Subkov \& Zilov, 1937), events occurring during drug administration correspond to a Pavlovian conditioning trial. Cues accompanying the drug effect function as conditional stimuli (CSs), and the direct drug effect constitutes the unconditional stimulus (UCS). Prior to any learning, this UCS elicits responses that compensate for drug-induced disturbances. These responses that compensate for the drug effect are unconditional responses (UCRs). After some pairings of the predrug CS and pharmacological UCS, the drug-compensatory responses are elicited as conditional responses (CRs).

We (see Siegel, 1991) and others (e.g., Obál, Vicsay, \& Madarász, 1965; Poulos \& Cappell, 1991) have hypothesized that, when a drug is administered in the context of the usual drug-administration cues, these drug-compensatory CRs contribute to tolerance; that is, they attenuate the drug effect. Moreover, when a drug is not administered in the context of the usual drug-paired cues, these CRs are expressed as "withdrawal symptoms." On the basis of the conditioning analysis of tolerance and withdrawal symptoms, then, these phenomena should be more pronounced in the context of the usual drug administration cues than in the context of alternative cues.

There are many demonstrations of context specificity of tolerance in which the drug-experienced organism is less responsive to the drug if it is administered in the drugassociated environment than if it is administered elsewhere. Such context specificity of tolerance was originally demon-

This research was supported by a grant from the Natural Sciences Engineering and Research Council of Canada to S.S. Correspondence concerning this article may be addressed to $S$. Siegel, Department of Psychology, McMaster University, Hamilton, ON L8S 4K1, Canada (e-mail: siegel@mcmaster.ca). strated with respect to tolerance to the analgesic effect of morphine in a number of experiments by Mitchell and colleagues (e.g., Kayan, Ferguson, \& Mitchell, 1973; Kayan, Woods, \& Mitchell, 1969). Subsequent research has demonstrated context specificity with respect to tolerance to many effects of a variety of drugs, including ethanol (e.g., Seeley, Hawkins, Ramsay, Wilkinson, \& Woods, 1996), nicotine (e.g., Epstein, Caggiula, \& Stiller, 1989), opiates (reviewed by Siegel, 1991), benzodiazepines (reviewed by Siegel, 1986), pentobarbital (e.g., Cappell, Roach, \& Poulos, 1981), phencyclidine (Smith, 1991), immunoenhancing drugs (Dyck, Driedger, Nemeth, Osachuk, \& Greenberg, 1987), and haloperidol (Poulos \& Hinson, 1982). It is seen in many species, from snails (Kavaliers \& Hirst, 1986) to humans (e.g., Dafters \& Anderson, 1982).

Similarly, there are demonstrations of context specificity of withdrawal symptoms. That is, rats display more behavioral withdrawal symptoms in a drug-paired environment than an alternative environment (e.g., Kelsey, Aranow, \& Matthews, 1990). In most demonstrations of the importance of the drug-paired environment to the display of withdrawal symptoms, "paired" rats are administered morphine in a distinctive environment $\left(\mathrm{E}_{1}\right.$; e.g., a room other than the animal colony), and saline in an alternative environment $\left(E_{2}\right.$, e.g., the home cage in the colony room). "Unpaired" rats are administered saline in $\mathrm{E}_{1}$, and morphine in $E_{2}$. Typically, morphine is injected in ascending doses, terminating (in different experiments) at $40-75 \mathrm{mg} / \mathrm{kg}$. Anywhere from 1 to 10 days following the final morphine administration, rats are administered saline in $E_{1}$, and various signs of morphine withdrawal are tabulated. Context specificity of withdrawal is inferred if paired rats display more withdrawal behaviors than do unpaired rats.

Recently, Azorlosa and colleagues (Azorlosa, Hartley, \& Deffner-Rappold, 1994; Deffner-Rappold, Azorlosa, 
\& Baker, 1996) have reported that context specificity of withdrawal may be seen after a much smaller amount of morphine exposure than is typical. That is, after as few as seven $10-\mathrm{mg} / \mathrm{kg}$ morphine administrations (at $48-\mathrm{h}$ intervals), paired rats display more evidence of withdrawal when administered saline in $\mathrm{E}_{1}$ than do unpaired rats. Indeed, with some measures, more withdrawal is apparent in $E_{1}$ in rats that previously received $10-\mathrm{mg} / \mathrm{kg}$ morphine in this environment than in rats that received $75-\mathrm{mg} / \mathrm{kg}$ morphine in this environment (Deffner-Rappold et al., 1996). Although such a finding may reflect the context specificity of morphine withdrawal, there is another interpretation. It is possible that some apparent morphinewithdrawal behaviors are actually exploratory behaviors, and some cases of more withdrawal behaviors in $E_{1}$ by paired than by unpaired rats actually represent more exploration by paired-group subjects.

It is well established that rats explore a novel environment more than they do a familiar environment (see, e.g., Berlyne, 1955). Although paired and unpaired rats have the same exposure to $E_{1}$ and $E_{2}$, only paired rats are pretreated with morphine in conjunction with $\mathrm{E}_{1}$ placement. There is considerable evidence that if rats are narcotized during exposure to a particular environment, their exploration of that environment is attenuated. When subsequently tested while undrugged, they treat this environment as relatively novel (see Scoles \& Siegel, 1986).

Although there are various reasons why drugged exposure to an environment may be less effective than undrugged exposure in attenuating exploratory responses, one possibility is that the drug act as a restraint. Results of conditioned place preference experiments indicate that if a rat is restrained during exposure to a particular environment, it subsequently displays increased preference for that environment, and that this is due to restraint preserving the "novelty" of the environment (Carr, Fibiger, $\&$ Phillips, 1989). It may be that subjects receiving morphine in $E_{1}$ are prevented from engaging in exploratory behavior by the locomotor suppression of morphine. That is, morphine may be acting as a "pharmacological restraint" resulting in increased exploratory behaviors when rats are placed in $E_{1}$ in the absence of morphine.

Another reason why paired rats may explore $E_{1}$ on the test more than do unpaired rats is state dependency. Although rats in both groups have equal exposure to this test environment prior to actual testing, only paired rats are drugged during pretest exposures. For paired rats, then, the first exposure to $E_{1}$ in the undrugged state occurs on the test session, and they may treat this environment as they do a novel environment since they are now in a novel pharmacological state.

Some of the behaviors seen as indicative of opiate withdrawal, such as wet-dog shakes and piloerection (EmmettOglesby, Mathis, Moon, \& Lal, 1990), would appear to have little to do with exploratory behavior. However, one commonly reported symptom of opiate withdrawal, rearing (both front paws free of the floor), is also seen in response to novel stimuli. Several investigators have pre- sented rearing as a morphine-withdrawal behavior (e.g., Kelsey et al., 1990; MacRae \& Siegel, 1997). Indeed, rearing sometimes is the only measure that provides compelling evidence of context specificity of such withdrawalespecially withdrawal seen following minimal morphine exposure (see, e.g., Azorlosa et al., 1994; DeffnerRappold et al., 1996). Rearing has also been characterized as an exploratory/curiosity-related behavior (Berlyne, 1960), a fear/emotionality-related behavior (Archer, 1973), and the result of nonspecific CNS excitability (Lat \& Gollova-Hemon, 1969).

The present experiment was designed to incorporate many features of recent demonstrations of context-specific withdrawal (e.g., Deffner-Rappold et al., 1996). In addition, the design of the experiment also permitted comparison of behaviors seen in a morphine-paired environment and in a novel environment.

\section{METHOD}

\section{Subjects and Drugs}

The subjects were 60 male Sprague-Dawley rats, weighing between 325 and $400 \mathrm{~g}$ at the start of the experiment. All subjects were individually housed in plastic cages containing recycled paper bedding material, with food and water freely available (except during conditioning and test trials), and maintained on a 12:12-h photoperiod (lights on at 6:30 a.m.). All conditioning and testing took place during the light portion of the photoperiod.

Morphine sulfate was prepared as a $10-\mathrm{mg} / \mathrm{ml}$ solution. All saline injections were given equivolume to the corresponding morphine injection. Injections were subcutaneous in the dorsal surface of the neck.

\section{Environments, Design, and Procedure}

Environments. Morphine and saline were injected in one of three environments $\left(E_{1}, E_{2}\right.$, or $\left.E_{3}\right)$. $E_{1}$ was 1 of 6 identical, clear, acrylic chambers $(30 \times 30 \times 30 \mathrm{~cm})$ located in a distinctive, brightly illuminated room. These chambers were supported on stands, and a mirror was mounted under the chamber at a $45^{\circ}$ angle to allow observation of the rat from below, as well as directly through the walls of the chamber. $E_{2}$ was 1 of 12 identical clear plastic cages (like the home cage but with no bedding material) located in a dark, vented, soundattenuating enclosure (a drawer of a fireproof filing cabinet; see Siegel, Hinson, \& Krank, 1978). $E_{3}$ was the home cage in the colony room.

Design. Withdrawal behaviors were evaluated in all rats in $E_{1}$ on a test session following the conditioning phase of the experiment. Five groups of rats ( $n /$ group $=12$ ) differed in their treatments during this pretest conditioning phase. Rats assigned to the morphine paired (MP) group were injected with morphine in $E_{1}$ and saline in $E_{2}$, and rats assigned to the morphine unpaired (MU) group were injected with morphine in $E_{2}$ and saline in $E_{1}$. Rats assigned to the saline paired (SP) group were injected with saline in both $E_{1}$ and $E_{2}$. Thus, the present experiment, like earlier experiments, evaluated contextual contribution to putative drug withdrawal symptoms; more such symptoms should be displayed by MP than by MU rats. In addition, the design of the present experiment included two additional groups to evaluate the extent to which these symptoms seen in $E_{1}$ represent responding to a novel environment, rather than a drugpaired environment: Groups Morphine Novel (MN) and Saline Novel (SN). During conditioning, Group MN rats were injected with morphine in $E_{2}$ and saline in $E_{3}$, and Group $S N$ rats were injected with saline in both $E_{2}$ and $E_{3}$. These rats had no exposure to the test environment, $E_{1}$, during conditioning.

Procedure. The procedure was similar to that of DeffnerRappold et al. (1996), except that the conditioning phase consisted 
of 12 (rather than 11) days. Rats received two injections on each conditioning day. The first injection consisted of saline. The second injection, $4 \mathrm{~h}$ later, consisted of either morphine (Groups MP, MU, and $\mathrm{MN}$ ) or saline (Groups SP and SN). The morphine dose for first morphine injection was $5 \mathrm{mg} / \mathrm{kg}$, and for the second and subsequent injections, it was $10 \mathrm{mg} / \mathrm{kg}$ (Deffner-Rappold et al., 1996).

For injections in $E_{1}$ and $E_{2}$, rats were transported from the colony room to the distinctive environment and placed in the environment for $5 \mathrm{~min}$. They were then removed, injected, and replaced in the environment for an additional 55 min before being returned to their home cages in the colony room. For injections in $\mathrm{E}_{3}$ (the home cage), rats were simply removed from their cages, injected, and returned to their cages, without leaving the colony room.

Test trials took place 5 days after the final conditioning trial. Subjects were tested in groups of 6 . Each test trial consisted of a 5-min preinjection exposure to the testing environment, an injection of saline (equivolume to injections received on the final conditioning trial), and a 30-min postinjection observation period in the testing environment. The $30-\mathrm{min}$ postinjection interval was divided into five blocks of 6 min each. Following injection, each subject was observed for 1 min during each 6-min block in a cycling procedure, resulting in a total observation period of $5 \mathrm{~min}(1 \mathrm{~min}$ from each of five blocks) for each subject during the 30-min interval.

Analysis. The behaviors scored during testing were rearing (both front paws off the floor of the chamber, with body extended upward, with episodes of grooming that resulted in both front paws being off the floor not being scored as rearing; see Azorlosa et al., 1994; Falls \& Kelsey, 1989; MacRae \& Siegel, 1997), genital licking (licking of the external genitalia, presumably reflecting ejaculation; see Kelsey et al., 1990), ear wiping (during grooming, pulling both paws simultaneously over the ears from back to front; see MacRae \& Siegel, 1997), and jumping (all four paws off the ground simultaneously; see Kelsey et al., 1990). The number of feces excreted was also recorded.

\section{RESULTS AND DISCUSSION}

The mean frequency of rearing observed during testing for each group is displayed in Figure 1. A one-way analysis of variance of the data summarized in Figure 1 revealed a significant difference among groups $[F(4,55)=12.9$, $p<.001]$. Subsequent Fisher's LSD tests revealed that Group MP, Group MN, and Group SN all reared more frequently than Group MU and Group SP, and that Group MP reared more frequently than Group SN (all $p s<.05$ ). There were no other significant between-group differences, either in the rearing measure, or in any other measure. In fact, the other behaviors scored during testing occurred only infrequently. Few rats displayed any of these other behaviors, and the mean occurrence of each behavior per group was less than one.

The finding that Group MP rats reared more than Group MU rats is similar to other reports that rats conditioned with as little as $10-\mathrm{mg} / \mathrm{kg}$ morphine display more rearing in the morphine-paired environment than in a saline-paired environment (Azorlosa et al., 1994; DeffnerRappold et al., 1996). Although it is tempting to interpret this finding as evidence of environmentally elicited drug withdrawal, results obtained from the additional groups suggest caution in applying this explanation. Group MN rats displayed about as much rearing as did Group MP rats, and, like Group MP rats, reared more than did Group MU rats. The difference between Groups $\mathrm{MN}$ and MU likely resulted from the fact that the test environment was novel for Group MN rats; thus they displayed rearing as an exploratory behavior. Indeed, the fact that Group SN rats reared more than did Group SP rats suggests that noveltyinduced rearing may be seen in rats with no prior history of morphine.

The primary implication of these results is that previous studies demonstrating context-specific increases in rearing upon termination of relatively low maintenance doses of morphine (e.g., Deffner-Rappold et al., 1996) cannot be taken as unequivocal evidence of context-specific withdrawal. Since paired-group rats were drugged during pretest exposures to the test context, the exten-

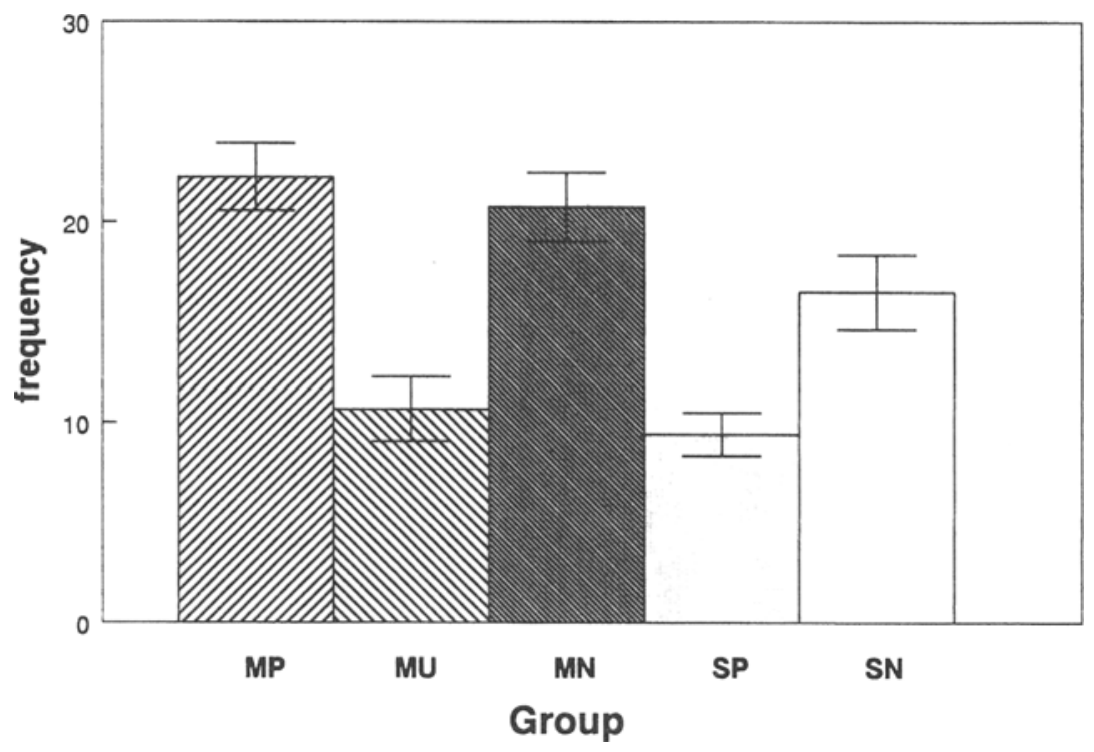

Figure 1. Mean ( $\pm 1 S E M$ ) frequency of rearing observed in each group. 
sive rearing displayed by these rats may represent heightened exploration of the functionally novel test context.

The phenomenon of context-specific withdrawal is one that merits further study. This phenomenon has been reported in human clinical studies (O'Brien, Ehrman, \& Ternes, 1986), and it has been suggested that contextual cues may play a significant role in the relapse to drug use often seen in human drug users following a period of abstinence (Siegel, 1989). Although the results of the present study do not rule out the interpretation of rearing as an index of context-specific withdrawal distress, it appears that this interpretation may be problematic where relatively low maintenance doses are used. The fact that there was a significant, although small, difference in frequency of rearing between Group MP and Group SN may suggest that there is some form of interaction between the effects of stimulus novelty of the environment and the elicitation of context-specific withdrawal in previously drug-paired environments.

\section{REFERENCES}

ARCHER, J. (1973). Tests for emotionality in rats and mice: A review. Animal Behavior, 21, 205-235.

Azorlosa, J. L., Hartley, N. E., \& DefFner-Rappold, C. (1994). Context-specific morphine tolerance and withdrawal: The effects of interdose interval. Psychobiology, 22, 304-311.

BERLYNE, D. E. (1955). The arousal and satiation of perceptual curiosity in the rat. Journal of Comparative \& Physiological Psychology, 48, 238-246.

Berlyne, D. E. (1960). Conflict, arousal, and curiosity. New York: McGraw-Hill

Cappell, H., Roach, C., \& Poulos, C. X. (1981). Pavlovian control of cross-tolerance between pentobarbital and ethanol. Psychopharmacology, 74, 54-57.

Carr, G. D., Fibiger, H. C., \& Phillips, A. G. (1989). Conditioned place preference as a measure of drug reward. In J. M. Liebman \& S. J. Cooper (Eds.), The neuropharmacological basis of reward (pp. 264-319). Oxford: Oxford University Press, Clarendon Press.

DAFTERS, R., \& ANDERSON, G. (1982). Conditioned tolerance to the tachycardia effect of ethanol in humans. Psychopharmacology, 78, 365-367.

Deffner-Rappold, C., Azorlosa, J. L., \& Baker, J. D. (1996). Acquisition and extinction of context-specific morphine withdrawal. Psychobiology, 24, 219-226.

DWORKIN, B. R. (1993). Learning and physiological regulation. Chicago: University of Chicago Press.

Dyck, D. G., Driedger, S. M., Nemeth, R., Osachuk, T. A. G., \& GreENBerG, A. H. (1987). Conditioned tolerance to drug-induced (poly I:C) natural killer cell activation: Effects of drug dosage and context specificity parameters. Brain, Behavior, \& Immunity, 1, 251-266.

Emmett-Oglesby, M. W., Mathis, D. A., Moon, R. T. Y., \& Lal, H. (1990). Animal models of drug withdrawal symptoms. Psychopharmacology, 101, 292-309.

Epstein, L. H., Caggiula, A. R., \& Stiller, R. L. (1989). Environmentspecific tolerance to nicotine. Psychopharmacology, 97, 235-237.

FALLS, W. A., \& KelSEY, J. E. (1989). Procedures that produce contextspecific tolerance to morphine in rats also produce context-specific withdrawal. Behavioral Neuroscience, 103, 842-849.

KAVALIERS, M., \& Hirst, M. (1986). Environmental specificity of tolerance to morphine-induced analgesia in a terrestrial snail: Generalization of a behavioral model of tolerance. Pharmacology, Biochemistry \& Behavior, 25, 1201-1206.
Kayan, S., Ferguson, R. K., \& Mitchell, C. L. (1973). An investigation of the pharmacologic and behavioral tolerance to morphine in rats. Journal of Pharmacology \& Experimental Therapeutics, 185, 300-306.

Kayan, S., Woons, L. A., \& Mitchell, C. L. (1969). Experience as a factor in the development of tolerance to the analgesic effect of morphine. European Journal of Pharmacology, 6, 333-339.

Kelsey, J. E., Aranow, J. S., \& Matthews, R. T. (1990). Contextspecific morphine withdrawal in rats: Duration and effects of clonidine. Behavioral Neuroscience, 104, 704-710.

Lat, J., \& Gollova-Hemon, E. (1969). Permanent effects of nutritional and endocrinological intervention in early ontogeny on the level of nonspecific excitability and on lability (emotionality). In E. Tobach (Ed.), Experimental approaches to the study of emotional behavior (Annals of the New York Academy of Sciences, Vol. 159, pp. 710-719). New York: New York Academy of Sciences.

MACRAE, J. R., \& SIEGEL, S. (1997). The role of self-administration in morphine withdrawal in rats. Psychobiology, 25, 77-82.

Obál, F., ViCSAY, M. S., \& Madarász, I. (1965). Role of a central nervous mechanism in the acquired tolerance to the temperature decreasing effect of histamine. Acta Physiologica Academiae Scientiarum Hungaricae, 30, 15-29.

O'Brien, C. P., Ehrman, R. N., \& Ternes, J. W. (1986). Classical conditioning in human opioid dependence. In S. R. Goldberg \& I. P. Stolerman (Eds.), Behavioral analysis of drug dependence (pp. 329-356). Orlando, FL: Academic Press.

Poulos, C. X., \& Cappell, H. (1991). Homeostatic theory of drug tolerance: A general model of physiological adaptations. Psychological Review, 98, 390-408.

Poulos, C. X., \& Hinson, R. E. (1982). Pavlovian conditional tolerance to haloperidol catalepsy: Evidence of dynamic adaptation in the dopaminergic system. Science, 218, 491-492.

RAMSAY, D. S., \& WoODS, S. C. (1997). Biological consequences of drug administration: Implications for acute and chronic tolerance. Psychological Review, 104, 170-193.

SCOLES, M. T., \& Siegel, S. (1986). The potential role of saline trials in morphine-induced place-preference conditioning. Pharmacology, Biochemistry \& Behavior, 25, 1169-1173.

Seeley, R. J., Hawkins, M. H., Ramsay, D. S., Wilkinson, C. W., \& Woods, S. C. (1996). Learned tolerance to the corticosteroneincreasing action of ethanol in rats. Pharmacology, Biochemistry \& Behavior, 55, 269-273.

SIEGEL, S. (1986). Environmental modulation of tolerance: Evidence from benzodiazepine research. In H. H. Frey, W. P. Koella, W. Froscher, \& H. Meinardi (Eds.), Tolerance to beneficial and adverse effects of antiepileptic drugs (pp. 89-100). New York: Raven.

SIEGEL, S. (1989). Pharmacological conditioning and drug effects. In A. J. Goudie \& M. Emmett-Oglesby (Eds.), Psychoactive drugs (pp. 115180). Clifton, NJ: Humana.

SIEGEL, S. (1991). Feedforward processes in drug tolerance. In R. G. Lister \& H. J. Weingartner (Eds.), Perspectives in cognitive neuroscience (pp. 405-416). New York: Oxford University Press.

Siegel, S., Hinson, R. E., \& Krank, M. D. (1978). The role of predrug signals in morphine analgesic tolerance: Support for a Pavlovian conditioning model of tolerance. Journal of Experimental Psychology: Animal Behavior Processes, 4, 188-196.

Sмiтн, J. B. (1991). Situational specificity of tolerance to decreased operant responding by morphine and 1 -nantradol. Psychopharmacology, 103, 115-120.

Subkov, A. A., \& Zilov, G. N. (1937). The role of conditioned reflex adaptation in the origins of hyperergic reactions. Bulletin de Biologie et de Médicine Expérimentale, 4, 294-296.

(Manuscript received October 14, 1997; revision accepted for publication November 24,1997 .) 